\title{
Photo-oxidation stability of microcapsules in thermochromic prints
}

\author{
Mirea Rožić ${ }^{1}$, Marina Vukoje ${ }^{1}$ \\ University of Zagreb, Faculty of Graphic Arts, Getaldićeva 2, Zagreb, Croatia \\ mirela.rozic@grf.hr
}

\begin{abstract}
In this paper, photochemical stability of two thermochromic prints was investigated: vegetable oil based offset and UV curing screen printing ink. The obtained preliminary results can be used for further detailed examination of prints stability. It is well known that thermochromic printing inks are very unstabile when exsposed to UV irradiance and this is why they are mainly used for applications that are not directly exposed to sunlight. The results of the study show the heterogeneous nature of photo-oxidative degradation of thermochromic prints, and the opposite behaviour of photo-oxidation can be noticed comparing examined prints. Microcapsules in the UV curable screen print by fixation with polar polymer binder can create a new product stable to photo-oxidation. For this reason, the areas where the microcapsules and binder are bonded together are stable. Degraded only areas where binder is not related to microcapsules. Microcapsules in offset print do not have the ability to create new stabile forms due to smaller polarity and different chemical composition of the offset oxidized binder. In the offset print, the microcapsules are the least photo-oxidative stable and also cause lower photo-oxidative stability of the binder in contact with them. Cavities are formed in the areas where microcapsules are in contact with the binder, while the areas in which the binder is not in contact with microcapsules are not degraded.
\end{abstract}

Key words: photo-oxidation, thermochromic, print, offset print, UV curable screen print

\section{Introduction}

Polymeric materials are susceptible to long-lasting and accelerated degradation processes, resulting in the deterioration of many properties from mechanical, chemical, thermal or electrical, to changes in color and appearance. Degradation is, therefore, any process that leads to deterioration of one or more polymer properties and long-term degradation means aging of the material. Changes occurring during degradation, primarily depends upon the type of polymers and additives and therefore the rate of degradation process will never occur in the same way (Yousif and Haddad, 2013). Polymer degradation can be caused by heat (thermal degradation), light (photodegradation), ionizing radiation (radio degradation), mechanical action, or by fungi, bacteria, yeasts, algae, and their enzymes (biodegradation). The overall light-initiated process in the presence of oxygen generally is referred to as oxidative photodegradation or photo-oxidation. These are very similar since they all involve chemical reactions that result in bond scission (Feldman,1983).

The degradation of polymers usually starts at the outer surface and penetrates gradually into the bulk of the material (Feldman,1983).

Photodegradation is degradation under the influence of light, i.e. electromagnetic radiation: ultraviolet (UV) wavelengths of 100 to $380 \mathrm{~nm}$ and visible wavelengths of 380 to 750 $\mathrm{nm}$. In order to achieve the initiation of photodegradation, the molecule must absor light 
energy, which means that molecules must contain chemical structures that absorb light in the electromagnetic spectrum (Yousif and Haddad, 2013; Anna et al., 2001; Zahra et al. , 2008).

For durable materials, like most coatings and plastics, short-wave UV is the primary cause of primary covalent bonds cleavlege in the polymer chain. For long-wave UV, the binding energy of $\mathrm{C}-\mathrm{C}$ bond is approximately equal to $330 \mathrm{~kJ} / \mathrm{mol}$, which corresponds to irradiance of $360 \mathrm{~nm}$ wavelength. Many structural polymers containing carbonyl group: polyesters, polyurethanes, polyamides are susceptible to this kind of degradation. For less durable materials, like many dyes and pigments, longer wave UV, and even short-wave visible light, can cause significant damage (Feldman,1983).

Many factors are responsible for causing photodegradation of polymeric materials. They may be divided into two categories: internal factors and external impurities. Internal factors include chromophoric groups that are introduced into macromolecules during polymerization processing and storage; they include: hydroperoxides, peroxides, carbonyl, unsaturated bonds $(\mathrm{C}=\mathrm{C})$ and catalyst residue. External impurities are: traces of solvents, catalyst,... etc., compounds from a polluted urban atmosphere and smog, e.g. polynuclear hydrocarbons, additives (pigments, dyes, thermal stabilizers, photostabilizers, ... etc.), traces of metals and metal oxides from processing equipment and containers, such as Fe, Ni or Cr (Feldman,1983).

The rate of degradation processes in polymers, apart from the chemical composition, is also significantly affected by the structural size, such as molecular mass and its distribution and crosslinking. Crosslinking increases the number of primary chemical bonds of the macromolecule and limits the mobility. The crystalline polymers are more stable to oxidative degradation than amorphous (Feldman,1983).

The oxidative degradation is reaction between polymers and oxygen at temperatures where heat detoration is negligible. Polymeric materials exposed to the influence of atmospheres are mainly decomposed by oxidation and hydrolytic processes initiated primarily by ultraviolet light. In addition, polymers that are highly resistant to oxygen influence are very easily subjected to photo-oxidation reactions. When the reaction starts, it gets very fast. For example, the polystyrene (the most resistant polymer to oxygen) is photo-oxidised by a radiation of 254 $\mathrm{nm}$ and by photo-oxidation - at $350 \mathrm{~nm}$ (Feldman, 1983).

Initiation begins with the absorption of light that causes photodegradation. Free radicals generated by photodegradation react with oxygen molecules, reactive radicals are formed, moreover peroxy radicals, ROO•; hydroperoxides $\mathrm{HOO} \bullet$; oxy radicals $\mathrm{RO} \bullet$, hydroxy radicals $\mathrm{HO} \bullet$ and alkyl radicals $\mathrm{R} \bullet$ which further undergo degradation to carbonyl and hydroxyl groups, water and CO2 (Feldman,1983; Yousif and Haddad, 2013; Zakharova and Chibisov, 2009).

Heterogeneity in polymer photo-oxidative degradation is a well-described and established phenomenon. Surface photodegradation characteristic of formation of strongly crosslinked surface structures hinders penetration of oxygen into the polymer bulk. Surface layers consisting of products formed predominantly by chain scission represent a weaker barrier for oxygen penetration than crosslinking (Pospišil, et al., 2006).

Thermochromic materials change their visible optical properties in response to temperature. Reversible thermochromic organic materials usually consist of at least three components the colorant, color developer and solvent. In order to achieve the desired effect the components are mixed in precisely determined proportions and usually encapsulated in a polymer envelope in order to protect the system for later applications (Urbaš, et al., 2001; Friškovec, et al., 2012; Granqvist, et al., 2009). The range of possible applications of such thermochromic materials increased dramatically with the process of microcapsulation which protects the system from unwanted reaction with the environment. Every microcapsule contains the entire system necessary for the creation of coloring (Urbaš, et al., 2001). Encapsulation with melamine resin is a common method widely described in the literature (Urbaš, et al., 2001; Changyou, et al., 2001; Alič et al., 2012; Maclaren and White, 2005). Only a few examples of encapsulation with epoxy resin have been reported (Seeboth, et al., 2007, Bamfield, 2001). Melamine resin or melamine formaldehyde 
(also shortened to melamine) is a thermosetting plastic material made from melamine and formaldehyde by polymerization. (Bamfield, 2001). A possible structure for the melamine resin is provided in Fig. 1. The linkage between melamine monomers can come from ether or methylene bridges. Not all the amino groups of the melamine monomers are substituted. Epoxy resins possess better temperature stability in comparision to melamine resins.

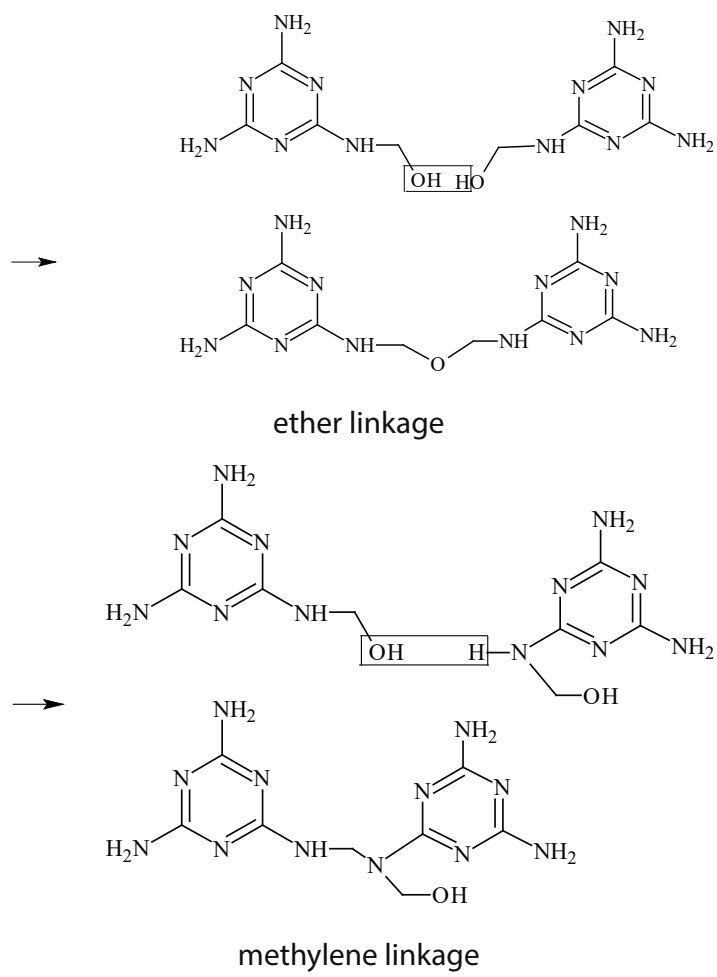

Fig.1. The structure of the melamine-formaldehyde polymer

Thermochromic printing inks are a mixture of thermochromic microcapsules and binders (Friškovec, et al., 2013). The functionality of thermochromic inks can be influenced by the UV radiation, temperatures above $200-230^{\circ} \mathrm{C}$ and aggressive solvents. The poor stability of thermochromic dyes when exposed to UV radiation limits the time of their exposure (Friškovec, et al., 2013). Many thermochromic dyes are of spirolactone type which contain carbonyl chromophoric groups (Oda, 2008; Oda 2005). The issues, which surround the application of thermochromic inks, is largely related to light resistance. This is the reason why today they are mainly used only for applications that are not directly exposed to sunlight. The increase of stability of thermochromic inks to UV radiation is the subject matter of an increasing number of studies.

Since in the available literature, stability of thermochromic dyes to photo-oxidation is mostly described, rarely the stability of thermochromic prints, this study investigates the photo-oxidation of two different thermochromic prints - offset and UV curable screen printing ink. Offset thermochromic printing ink as a binder contains vegetable oil that dries by oxidation with oxygen from the air, while thermochromic screen printing ink dries under UV radiation. Degradation of the prints was analyzed by scanning electron microscopy (SEM) analysis. A heterogeneous degradation of the prints has been proven.

\section{Material and methods}

\subsection{Thermochromic ink and printing method}

One commercially available leuco dye based offset ink (Chromatic Technologies, Inc.) and one commercially available leuco dye based UV curable screen printing thermochromic ink (Chromatic Technologies, Inc.) were applied. Thermochromic printing inks were printed on metal plates. For the production of offset print Prüfbau Multipurpose Printability Tester was used. Firstly the printing ink was distributed on the tester. The pressure during printing was $600 \mathrm{~N} / \mathrm{cm} 2$. The screen printing thermochromic ink was screen printed using the Siebdruckgeräte von Holzschuher K.G., Wuppertal, employing 60/64 mesh. All the samples were printed in the full tone. The printed samples were dried under the UV irradiance $(30 \mathrm{~W} / \mathrm{cm})$ using Technigraf Aktiprint L 10-1 device.

The activation temperature of offset thermochromic ink is $63^{\circ} \mathrm{C}$. Below its activation temperature, the print was coloured in burgundy and above its activation temperature the print was coloured blue. The activation temperature of UV curable screen printing thermochromic ink is $12^{\circ} \mathrm{C}$. Below its activation temperature, the print was coloured in orange and above its activation temperature the print was coloured in yellow. 


\subsection{UV radiation of the prints by xenon light}

For accelerated aging of the prints under xenon light the device Solarbox 1500e (CO.FO.ME. GRA) was used. This device enables a simulation of environmental conditions in the open and closed space, and ensures a control of temperature and radiation. All the samples were exposed to filtered xenon light in a period from 6 hours at a temperature of $60^{\circ} \mathrm{C}$. The indoor filter - (soda lime glass filter extra long life) was used for the simulation of conditions of internal exposure (equivalent to sunrays filtered through a windowpane).

\subsection{Scanning electron microscopy (SEM)}

The printed thermocromic surfaces before and after degradation were monitored using a FESEM Jeol 7000 field emission scanning electron microscope.

\section{Results}

Figure 2 shows SEM micrographs of offset print before photo-oxidation. SEM micrograph indicates relatively high amount of microcapsules in print, with average sizes from $1-2 \mu \mathrm{m}$.

a

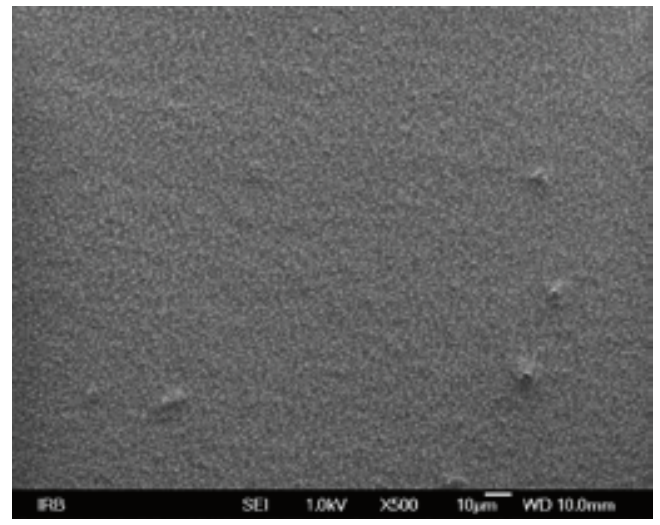

b

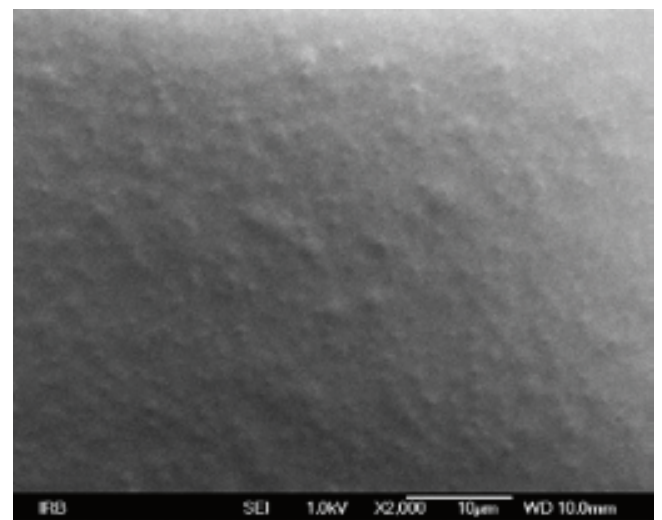

Figure 2 SEM micrographs of offset print before photo-oxidation (maginification of 500x and 2000x)

SEM micrograph of UV curable screen print (Fig. 3) indicates the greater amount of microcapsules with average sizes from 0.5 to $1 \mu \mathrm{m}$. Microcapsules in UV curable screen print are covered with thinner layer of ink binder compared to microcapsules in offset print.

a

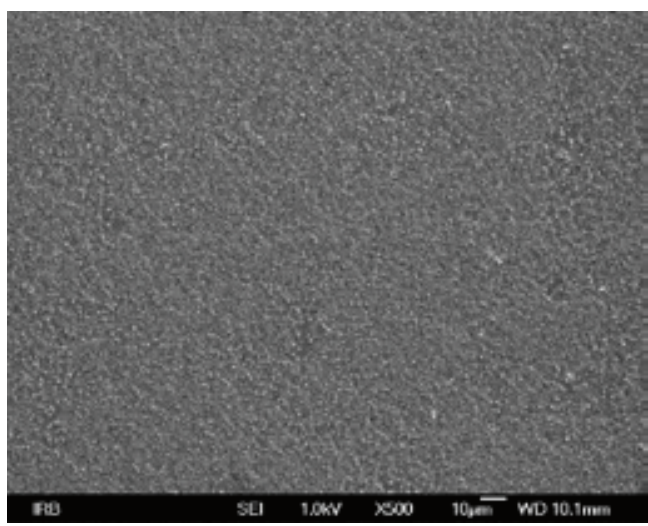

b

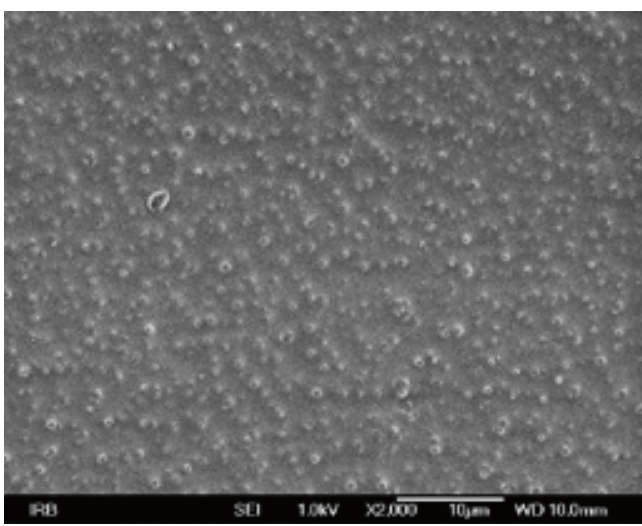

Figure 3 SEM micrographs of UV curable screen print before photo-oxidation (maginification of 500x and 2000x)

Figure 4 shows SEM micrographs of offset print after the process of photo-oxidation. The formation of wholes can be noticed in the areas where microcapsules are present. During the whole period of exposure to xenon light, there was no visible degradation of all print area. Degradation of areas in which printing ink binder is not in contact with microcapsules cannot be noticed. 
a

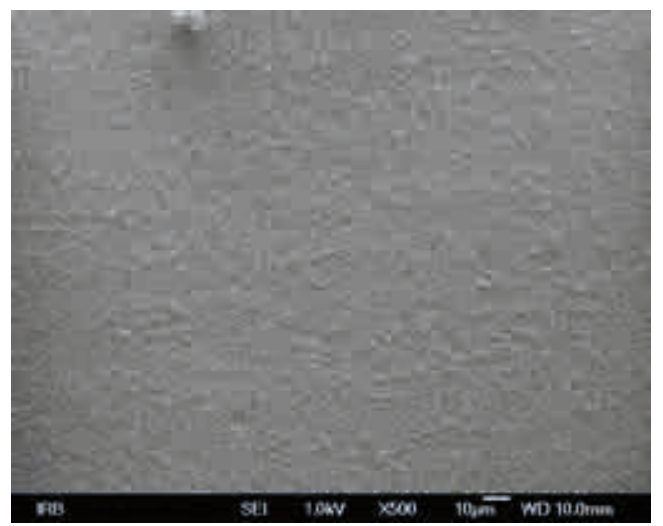

b

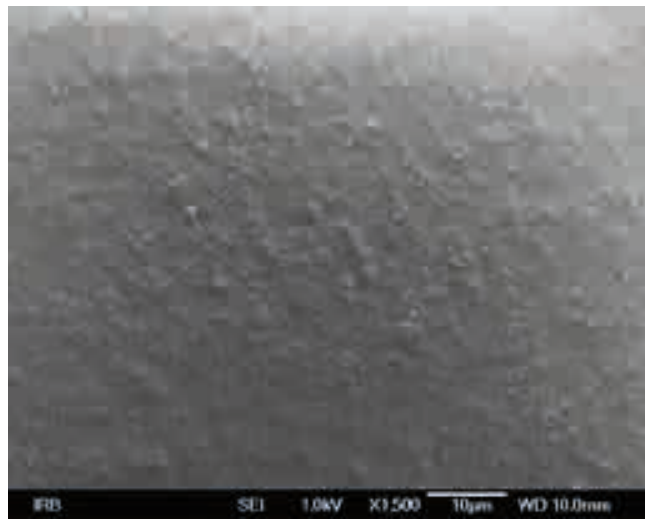

c

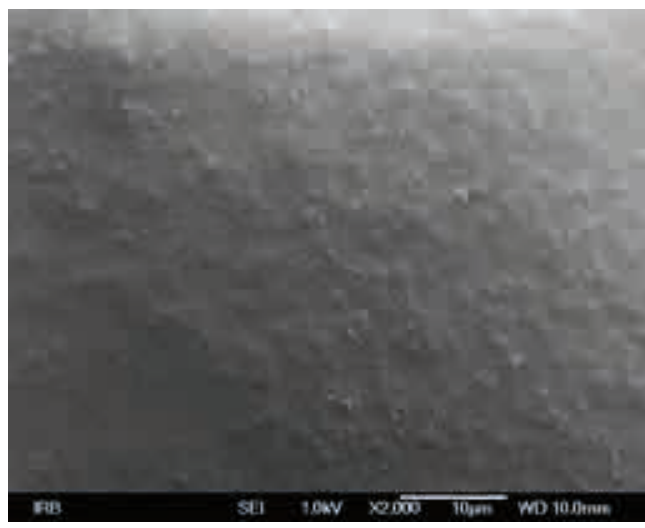

d

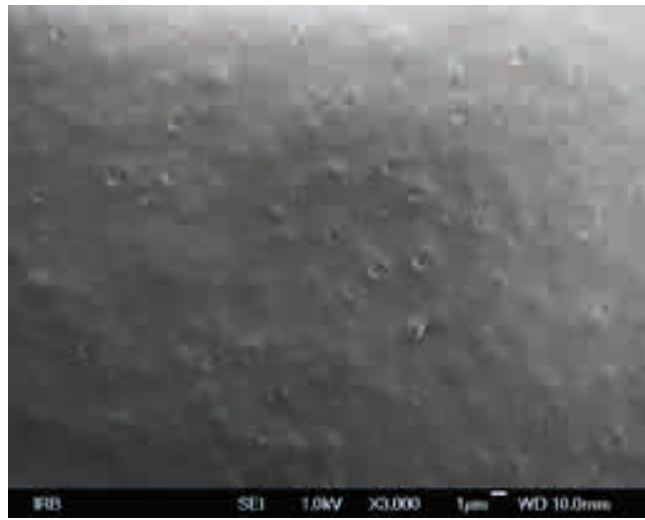

Figure 4 SEM micrographs of offset print after photooxidation (magnifications of 500x, 1500x, 2000x and $3000 \mathrm{x}$ )

Figure 5 shows SEM micrographs of UV curable screen prints after process of photo-oxidation.
In this case, the formation of wholes can't be noticed. Degradation of ink binder in the areas in which it's not in contact with microcapsules can be visible, in the form of irregular shapes with sizes of $1-2.5 \mu \mathrm{m}$. Comparing to microcapsules in offset print, microcapsules in UV screen print remained preserved. In addition, during exposure time, the detoration of the whole print area can't be seen.

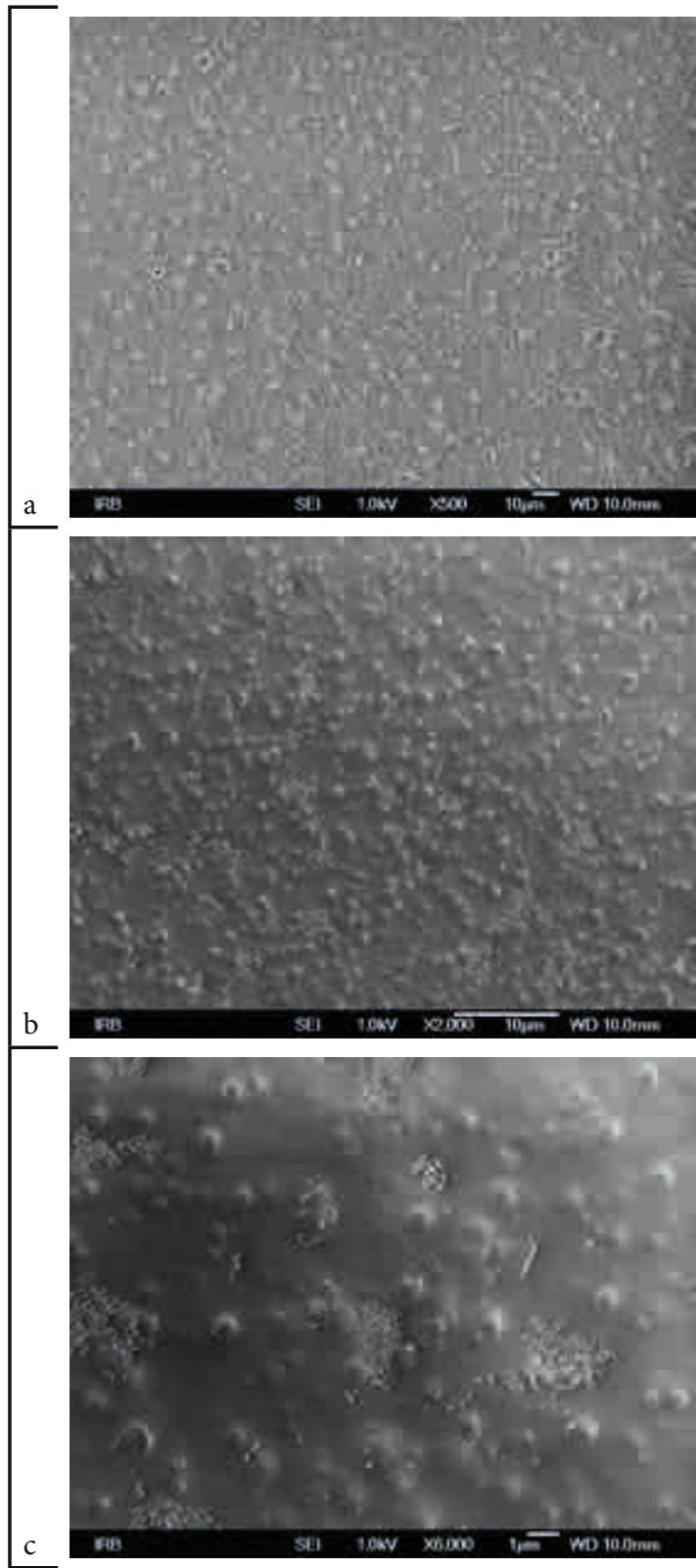

Figure 5 SEM micrographs of UV screen print after photo-oxidation (magnification of 500x, 2000x and $6000 \mathrm{x}$ )

\section{Discussion}

Binder in examined offset thermochromic printing ink is vegetable oil which dries by 
oxipolymerization process with oxygen from the air. Driers (Co and $\mathrm{Mn}$ ) are used to catalyse the oxidation drying of vegetable oils. The process involves the oxygen-induced free-radical polymerization of the unsaturated long chain acids. Oxygen attacks activated sities on the fatty acid hydrocarbon chain resulting in formation of peroxide/hydroperoxide intermediates. The final oxidation products are $\mathrm{R}-\mathrm{R}, \mathrm{R}-\mathrm{O}-\mathrm{R}$ and $\mathrm{R}-\mathrm{O}-\mathrm{O}-\mathrm{R}$ polymers. In addition to the linear propagation of polymerization cross-linking also occurs because of the presence of more than one active site in multiunsaturated and conjugated double bond oil molecules. The resulting polymers contain peroxide groups, unsaturation, catalyst residues which can cause oxidative photodegradation (Thompson, 2004). However, it has been observed that the degradation of the offset print is more pronounced at the areas where the microcapsules are located. Therefore, microcapsules accelerate the photo-oxidation of the offset printing ink binder.

UV drying inks dry instantaneously by absorbing photons of high energy ultraviolet light from an appropriate light source and then undergoing a chemical polymerization reactions. UV curing ink vehicles typically contain an unsaturated high-molecular-mass (800 - 2000) prepolymer and polyfunctional and monofunctional monomers which cross-link on exposure to UV radiation. A photoinitiator is necessary to start the cross-linking process. Photoinitiators for UV curing inks are generally related to benzophenone, which contain a carbonyl group. Acrylated resins are used predominantly in oligomer systems and their combinations include epoxy, polyester and urethane prepolymers. They all contain a carbonyl group (Thompson, 2004; Du, et al., 2017; Shanti, et al., 2017).

Degradation of UV curable screen print was noticed in the areas where microcapsules aren't located. Therefore, the microcapsules in this print stabilize the printing ink binder. The reason why there was no degradation of the print in the areas where the microcapsules are located, it can only be that the microcapsules in some way stabilize the binder. Hydrogen bond formation between the carbonyl groups of the binder and $-\mathrm{OH}$ and $-\mathrm{NH}(-\mathrm{NH} 2)$ groups of microcapsules melamine resin is possible.
Since the carbonyl groups are polar, formed hydrogen bonds are strong.

As demonstrated by (Bezrodnyi, et al., 2016) the aliphatic polyurethane polymer matrix of high polarity has a potential ability to bond covalently with the $-\mathrm{NH} 2$ and $-\mathrm{OH}$ substituent groups in the phenalenone dyes and a rigid fixation of the dye molecule with a polymer chain occurs. It causes higher photo-stability of dyes.

Research by (Moura, et al., 1997) has found that the possibility for altering the photodegradation characteristics of a dye polymer composite is to alter the physical situation of the dye. This is achieved by altering its intermolecular interaction characteristics: the state of aggregation of the dye, the strength of binding to the polymer, and the location of the dye within the polymer. These can all influence the rate of photodegradation.

Thus, the microcapsules in the UV curable screen print are protected from photo-oxidation due to the fixation on the polar binder by physical or chemical bonds. Consequently, the number of available carbonyl groups of the binder is reduced. This reaction is not possible with the offset polymeric binder. The offset binder contains peroxide groups which can form hydrogen bonds with $-\mathrm{OH}$ and $-\mathrm{NH}$ $(-\mathrm{NH} 2)$ groups of melamine resin, but they are due to the lower polarity of the peroxide groups weaker compared to the hydrogen bonds formed by linking with the carbonyl groups. In addition, the degree of crosslinking of the oxidized vegetable oil is obviously considerably lower and thus the diffusion of the oxygen molecules to the surface of the microcapsules is facilitated. Considering that microcapsules accelerate degradation of the binder, it is more likely that microcapsules degrade faster. This may be explained due to smaller sizes of microcapsules and their lower average molecular mass compared to average molecular mass of polymer binder.

\section{Conclusions}

In the UV curable screen print, the microcapsules show higher stability to photo-oxidation comparing to microcapsules present in offset print. The fixation of the polar polymer molecules of binder and microcapsules shell is possible. In addition, the formation of new 
product which doesn't contain any chromophore groups is possible which causes greater photo-stability of microcapsules and binders. Hence, heterogeneous photo-oxidation occurs - degradation of binder at sites where it is not bound to microcapsules.

Contrary, heterogeneous degradation was achieved for offset print - in areas where the binder was bound to the microcapsules was significantly degraded. The cavities were formed, indicating that photo-oxidation of binder and microcapsules occurred. The areas where the binder was not bound to the microcapsules remained preserved. This indicates that the microcapsules are considerably less stable. Oxygen molecules penetrate to chromophore groups of microcapsules causing the formation of free radicals and cleavage of microcapsules and binders molecules.

This study shows that many factors affect the photo-oxidation stability of thermochromic prints, such as chemical composition of the binder and the microcapsules, interactions between the printing ink binder and microcapsules and binder drying mechanism.

\section{References}

1. Alič, B., Šebenik, U., Krajnc, M., 2012. Microencapsulation of butyl stearate with melamineformaldehyde resin: effect of decreasing the $\mathrm{pH}$ value on the composition and thermal stability of microcapsules. eXPRESS Polymer Letters, 6 (10), 826-836.

2. Anna, P., Bertalan, Gy., Marosi, Gy., Ravadits, I., Maatoug, M.A., 2001. Effect of interface modification on the photo-stability of pigmented polyethylene films. Polymer Degradation and Stability, 73, 463-466.

3. Bamfield,2001. Chromic phenomena, technological applications of colour chemistry, RSC.

4. Bezrodnyi, V, Stratilat, M., Kosyanchuk, L., Negriyko, A., Klishevych, G., Todosiichuk, T., 2016. Solvation effects on spectral and photophysical properties of phenalenone dyes in polyurethane polymers. Journal of Polymer Research, 23 (106), 1-7.

5. Changyou, G., Moya, S., Lichtenfeld, H., Casoli,A., Fiedler, H., Donath, E., Möhwald, H., 2001. The decomposition process of melamine formaldehyde cores: the key step in the fabrication of ultrathin polyelectrolyte multilayer capsules. Macromolecular Materials and Engineering., 286, 355-361.

6. Du, L., Liu, Z., Jiang, S., 2017. Inkjet-printed CdTe quantum dots-polyurethane acrylate thin films. Hindawi Journal of Nanomaterials, Article ID 7409154, 5 pages.

7. Feldman, D., 1983. A review of: "M. Schnabel: Polymer degradation, principles and practical applications,
Hanser International, Munich, 1981, 227 pp.. Journal of Macromolecular Science: Part A - Chemistry, 19, 5.

8. Friškovec, M., Kulčar, R., Klanjšek Gundec,M., 2013. Light fastness and high-temperature stability of thermochromic printing inks. Coloration Technology, 129, 214-222.

9. Granqvist, C.G., Lansaker, P.C., Mlyuka, N.R., Niklasson, G.A., Avendano, E., 2009. Progress in chromogenics: new results for electrochromic and thermochromic materials and devices. Solar Energy Materials \& Solar Cells, 93, 2032-2039.

10. Maclaren, D. C., White, M. A., 2005. Design rules for reversible thermochromic mixtures, Journal of Materials Science, 40, 669- 676.

11. Moura, J. C. V. P., Oliveira-Campos, A. M. F., Griffiths, J., 1997. The effect of additives on the photostability of dyed polymers. Dyes and Pigments, 33 (3), 173-196.

12. Oda, H., 2005. New developments in the stabilization of leuco dyes: effect of UV absorbers containing an amphoteric counter-ion moiety on the light fastness of color formers. Dyes and Pigments, 66, 103-108.

13. Oda, H., 2008. Photostabilization of organic thermochromic pigments: action of benzotriazole type UV absorbers bearing an amphoteric counter-ion moiety on the light fastness of color formers. Dyes and Pigments, 76, 270-276.

14. Pospišil, J., Pilar, J., Billingham, N.C., Marek, A., Horak, Z., Nešpurek, S., 2006. Factors affecting accelerated testing of polymer photostability. Polymer Degradation and Stability, 91, 417-422.

15. Seeboth, A. Klukowska, R. Ruhmann, D. Lotzsch, Chinese Journal of Polimer Science, 25, 123 (2007)

16. Shanti, R., Hadi, A. N., Salim, Y. S., Chee, S. Y. Ramesh S., Ramesha, K., 2017. Degradation of ultra-high molecular weight poly(methyl methacrylate-co-butyl acrylate-coacrylic acid) under ultra violet irradiation. RSC Adv., 7, 112-120.

17. Thompson, B, 2004. Printing materials, Science and technology. Pira International, Hertfordshire.

18. Urbaš, R.,Milošević, R., Kašiković, Nj., Pavlović, Ž., Stanković Elesini, U., 2017. Microcapsules application in graphic arts industry: a review on the state-of-the-art. Iranian Polymer Journal, 26, 541561.

19. Zahra, A., Kish, M.H., Freeman, H., Kotek, R., Katbab, A.A., 2008. Photostability of isotactic polypropylene containing monoazo pigment. Journal of Applied Polymer Science, 108, 2950-2957.

20. Zakharova, G. V., Chibisov, A. K., 2009. Photostability of Pseudoisocyanine J Aggregates

21. in polymer films and ways of its improvement. High Energy Chemistry, 43 (4), 294-297.

22. Yousif, E., Haddad, R., 2013. Photodegradation and photostabilization of polymers, especially polystyrene: review. Yousif and Haddad SpringerPlus, 2(398), 32 pages. 
This page was left blank intentionally! 